ATUALIZAÇ̃̃̃O

\title{
TORQUE TENO VÍRUS (TTV)
}

E POLUIÇÃO FECAL

\section{Andréia Dalla Vecchia ${ }^{1}$ e Fernando Rosado Spilki ${ }^{2}$}

\section{RESUMO}

A pesquisa de agentes virais em amostras de água coletadas no ambiente teve seu início há aproximadamente sessenta anos. Inicialmente, o enfoque dos trabalhos estava voltado para a detecção dos enterovírus. Posteriormente outros vírus, especialmente entéricos com relevante impacto em saúde pública, tornaram-se alvo de pesquisa quanto à sua presença em amostras de água. Os agentes virais, normalmente associados a gastroenterites e hepatites, têm como principais características excreção em altas quantidades nas fezes de indivíduos infectados, elevada resistência à inativação no ambiente e ausência de replicação fora do hospedeiro. Tais características biológicas os tornam excelentes marcadores da contaminação ambiental oriunda da colonização de novas áreas pelo ser humano e podem atestar falhas nas estratégias de saneamento básico. Mais recentemente, o Torque Teno vírus (TTV) vem sendo considerado um candidato em potencial a agente biológico marcador no estudo de contaminação fecal da água por apresentar as características anteriormente mencionadas para os vírus entéricos e estar amplamente disseminado na população humana.

DESCRITORES: Torque Teno vírus. TTV. Biomarcadores. Impacto ambiental.

\section{INTRODUÇÃO}

Vírus entéricos, tais como os Poliovírus, Rotavírus, Calicivírus e o Vírus da hepatite $\mathrm{A}$ e até potenciais zoonoses como a hepatite $\mathrm{E}$, compreendem os agentes virais que estão presentes no trato gastrointestinal humano e são transmitidos por via fecal-oral em razão da contaminação do solo, de alimentos e da água (Teixeira \& Leal, 2002; Tavares et al., 2005). Estes vírus são importantes agentes etiológicos

1 Hospital das Clínicas de Porto Alegre, Porto Alegre, RS; Aluna do Programa de Pós-Graduação Mestrado em Qualidade Ambiental, Centro Universitário Feevale, Novo Hamburgo, RS.

2 Programa de Pós-Graduação Mestrado em Qualidade Ambiental, Centro Universitário Feevale, Novo Hamburgo, RS, Brasil.

Endereço para correspondência: Fernando Rosado Spilki, Instituto de Ciências da Saúde, FEEVALE, Rodovia RS-239, 2755. CEP 93352-000 Novo Hamburgo, RS, Brasil.. E-mail: fernandors@feevale.br

Recebido para publicacao em: 7/4/2009. Revisto em 25/8/2009. Aceito em: 25/9/2009. 
de gastroenterites e hepatites em humanos e, em razão de sua veiculação hídrica, são motivo de preocupação constante em saúde pública.

\section{AGENTES VIRAIS COMO MARCADORES DE QUALIDADE DA ÁGUA}

No atual sistema de monitoramento da qualidade da água, a Escherichia coli e demais microrganismos pertencentes ao grupo dos coliformes termotolerantes são as bactérias marcadoras da poluição fecal em águas e esgoto (Resolução CONSEMA $n^{\circ}$ 128/2006). Tal indicador tem se mostrado insuficiente, pois esses microrganismos podem não atestar o risco virológico no ambiente (Dore et al., 2000; Duran et al., 2002; Haramoto et al., 2005b; Griffin et al., 2008). Os enterovírus, adenovírus e outros vírus entéricos podem ser encontrados em esgotos sanitários contaminando o ambiente aquático que futuramente poderia ser usado como fonte de água potável. A contaminação viral de águas subterrâneas e poços também tem sido relatada (Teixeira \& Leal, 2002).

Os vírus entéricos são em geral eliminados em quantidades relativamente grandes pelas fezes de indivíduos infectados, podendo atingir títulos virais de aproximadamente $10^{8}$ a $10^{11}$ partículas virais por grama de fezes, conforme o agente viral analisado, por isso representam potencial risco à saúde da população (Mehnert, 2003). A presença desses patógenos pode estar associada à ocorrência de doenças em indivíduos susceptíveis (Tavares et al., 2005), o que constitui um grande obstáculo às estratégias de uso e reuso da água.

Os vírus excretados pela via fecal são, em geral, não envelopados, o que lhes confere elevada resistência a condições ambientais adversas. Podem permanecer viáveis por longos períodos na água, até mesmo em ambiente marinho e em águas subterrâneas, resistindo a condições ambientais desfavoráveis ou letais para outros microrganismos, tais como extremos de $\mathrm{pH}$, elevadas temperaturas $\mathrm{e}$ elevada salinidade (Ley et al., 2002; Griffin et al., 2008).

Embora não se multipliquem quando estão dispersos no ambiente por serem parasitos intracelulares obrigatórios, os vírus não envelopados são geralmente mais resistentes às intempéries do que os procariotos, bem como aos métodos químicos e físicos utilizados no tratamento de água e esgoto. Assim, os vírus apresentam vantagens em relação às bactérias como marcadores de eficiência do processo de descontaminação da água, já que os procariotos são mais susceptíveis aos processos de tratamento químico-físico e à degradação ambiental (Jiang et al., 2007). Muitos vírus entéricos são mais resistentes do que bactérias aos processos de desinfecção por tratamento de cloração e radiação ultravioleta; as bactérias, por sua vez, são mais facilmente removidas pelos processos de filtração (Griffin et al., 2008). Desse modo, a ausência ou baixa concentração de bactérias de presumida origem fecal na água não significa ausência de vírus entéricos (Jiang et al., 2007).

A falta de rotinas de análise virológica pelos serviços de monitoramento dos sistemas de fornecimento de água potável é problema mundial. Acredita-se que 
esse fato venha contribuindo para os episódios de surtos de gastroenterites e para a elevada prevalência de hepatites dos tipos A e E, especialmente nos países em desenvolvimento (Teixeira \& Leal, 2002).

\section{TORQUE TENO VÍRUS}

O Torque Teno vírus (TTV) é um vírus não envelopado, pequeno, composto por DNA fita simples, circular com polaridade negativa e formado por 3,4 - 3,9 kb de comprimento (Mushahwar et al., 1999; Okamoto et al., 2000a,b; Watanabe et al., 2005; Devalle \& Niel, 2005) e diâmetro de 30-32 nm (Itoh et al., 2000). Além disso, este vírus pode exibir características similares aos vírus entéricos patogênicos (Griffin et al., 2008). O genoma é bastante reduzido, sendo composto por apenas 3.852 nucleotídeos (Kakkola, 2008). Recentemente, o TTV foi classificado no gênero Anellovirus e família Circoviridae (Diniz-Mendes et al., 2004), tendo sido detectado não apenas em humanos, mas também em outros mamíferos, tais como felinos, caninos e suínos (Devalle \& Niel, 2005). Há também achados de fragmentos genômicos de DNA de TTV em chimpanzés, primatas e animais de fazenda (Okamoto et al., 2000). O TTV já foi detectado em bovinos, suínos, aves, ovinos e também em vários primatas não humanos (Brassard et al., 2008). Estudos identificaram a presença de TTV suíno em até $66 \%$ de amostras coletadas de animais sadios. O genoma do TTV de origem suína é menor e, quando comparado aos isolados de humanos, possui similaridade em torno de $45 \%$ em relação às sequências genômicas do TTV humano (Mckeown et al., 2004).

Apesar do pouco conhecimento sobre suas propriedades biológicas, sabe-se que o vírus apresenta considerável diversidade genética, tendo sido encontrados cerca de quarenta genótipos, os quais podem ser classificados em cinco grupos que teoricamente podem apresentar diferentes níveis de virulência (Maggi et al., 2007). Embora a associação do TTV com indução de doença em humanos seja discutível, estudos indicam que o genótipo 1, especificamente, tem possível participação nestes processos (Watanabe et al., 2005).

\section{HISTÓRICO E IMPORTÂNCIA CLÍNICA DO TTV EM SERES HUMANOS}

Acredita-se que seu nome esteja associado às iniciais (TT) do primeiro paciente investigado pelo grupo de pesquisadores, embora essas iniciais também possam representar transfusion-transmitted virus (Watanabe et al., 2005; Nasser, 2007). O TTV foi isolado primeiramente pelo pesquisador japonês Nishizawa e seus colaboradores (1997), a partir de amostras biológicas de pacientes com hepatite pós-transfusional de etiologia desconhecida. Posteriormente, foi detectado em diversos países (Okamoto et al., 2000; Bassit et al., 2002, Devalle \& Niel, 2005; Diniz-Mendez et al. 2004).

Inicialmente suspeitou-se que o TTV causava hepatites, mas recentes estudos indicam que este vírus pode não provocar sérios problemas de saúde (Abe 
et al., 1999). Outros estudos, porém, indicam que vários genótipos podem ser responsáveis por provocar doenças em humanos (Takahashi et al., 1998).

A presença do TTV foi identificada em aproximadamente $50 \%$ dos casos de hepatites crônicas ou agudas e $12 \%$ de doadores de sangue em estudo realizado no Japão (Okamoto et al., 1998). Em estudo realizado no Brasil por Bassit et al. (2002), foi observada a presença do TTV em $85,3 \%$ dos doadores de sangue e em $81,2 \%$ das crianças e adolescentes pesquisados. Tais resultados, além de um grande número de relatos da detecção do vírus em indivíduos saudáveis e da ausência de um modelo experimental adequado para a infecção, não permitem confirmar a participação do TTV como agente etiológico de alguma doença específica em humanos, uma vez que o TTV é um vírus presente em mais de $80 \%$ da população em todo o mundo (Devalle \& Niel, 2005).

O TTV causa infecções crônicas e está presente no plasma, tecidos e fluidos corporais de mais de $80 \%$ de doadores de sangue saudáveis (Maggi et al., 2007) e estudos têm mostrado que o vírus persiste por períodos prolongados ou indefinidamente no plasma de indivíduos infectados. Além disso, de acordo com o estudo feito por Nasser (2007), o TTV é mais prevalente em indivíduos soropositivos ao HIV em comparação com indivíduos saudáveis. Embora ainda a significância clínica da associação do TTV com HIV necessite ser elucidada, esse estudo sugere que a presença do TTV pode estar relacionada a uma diminuição da carga viral do HIV em indivíduos portadores.

No Brasil, o TTV foi detectado em pacientes com doenças hepáticas crônicas nas Regiões Sudeste e Norte do país (Pinho et al., 1998). Outros estudos têm evidenciado a presença DNA de TTV em tecidos, fluidos corporais (saliva, urina, fezes e sêmen) e em vários órgãos humanos como fígado, bílis, medula óssea, nodo de linfa, músculo, tireóide, glândulas, pulmão, baço, pâncreas, rim, região gástrica, cérebro e outros (Kakkola et al., 2008).

\section{EPIDEMIOLOGIA}

Ainda que inicialmente se acreditasse que a principal via de transmissão do TTV fosse a transfusão sanguínea, a presença de TTV nas fezes de indivíduos saudáveis é ubíqua, sendo presumível que a infecção está amplamente disseminada na população humana. Assim, o TTV, por ser um vírus não envelopado e possuir excreção por diferentes vias, incluindo a via fecal, pode ser considerado como um interessante candidato a agente biológico marcador no estudo de contaminação fecal de águas, tal como ocorre com outros microrganismos dotados de disseminação hídrica (Fong \& Lipp, 2005). Segundo Berns (1996), os tratamentos com virucidas utilizados para inativar vírus envelopados, como solvente-detergente com aquecimento a seco a $95^{\circ} \mathrm{C} / 96$ horas, demonstram ser pouco efetivos na destruição da estrutura viral.

Embora estudos complementares sejam necessários para uma melhor compreensão deste agente, pesquisas moleculares apontam a presença do TTV 
em $60 \%$ a $80 \%$ da população suína em análises de amostras de soro. Sendo a epidemiologia do TTV pouco compreendida, suspeita-se que a rota fecal-oral represente uma importante via de transmissão do TTV também em suínos. Entretanto, estudos têm demonstrado uma baixa prevalência do TTV em bovinos, o que poderia ser explicado pela replicação viral em baixos títulos nesses animais e pela elevada variabilidade das amostras virais que afetaria os limiares de detecção por métodos moleculares. Assim, futuras pesquisas devem determinar a prevalência do TTV na espécie bovina e elucidar os fatores que afetam as diferenças na prevalência TTV em suínos e bovinos, ainda que fatores ambientais possam estar relacionados (Brassard et al., 2008).

\section{DETECÇÃO MOLECULAR DE VÍRUS EM AMOSTRAS AMBIENTAIS}

Inicialmente, para a pesquisa de vírus em ambiente aquático utilizava-se grande volume de água, chegando a serem usados em torno de 500 litros de amostra para a detecção viral (Haramoto et al. 2004). Outros estudos sugerem como recomendável o uso de 10 litros de água como amostra, com a coleta em um processo de concentração das amostras por filtros e eluição, centrifugação ou outras metodologias com o fim de concentrar as escassas partículas virais presentes (Haramoto et al., 2005b). Estudos recentes têm mostrado que a quantidade de amostra pode ser significativamente reduzida comparativamente a estudos anteriores, chegando em alguns deles a $500 \mathrm{~mL}$, como descreveram Haramoto et al. (2005b) e Albinana-Gimenez et al. (2009). Este último estudo mostrou que quantidades menores de amostra facilitam a detecção viral por métodos moleculares, tendo sido comparados volumes de amostra de $40 \mathrm{~mL}, 1$ litro, 10 litros e 50 litros. O estudo mostrou que amostras de 10 litro e 50 litros apresentaram a menor taxa de detecção viral e uma alta inibição na reação em cadeia da polimerase (PCR), dada a concentração de inibidores da reação no processo, obtendo-se limites de deteç̧ão de 2,5 $\times 10^{1} \mathrm{GC} / \mathrm{L}$ para $50 \mathrm{~L} \mathrm{e} 1,25 \times 10^{2} \mathrm{GC} / \mathrm{L}$ para 1 e $10 \mathrm{~L}$. Encontrou-se, dessa forma, uma maior sensibilidade analítica na detecção em amostras da ordem de $1 \mathrm{e}$ 10L. Além disso, diversos volumes de amostra de água de rio com elevada turbidez e significativa contaminação viral fecal foram comparados e o volume de $1 \mathrm{~L}$ foi o que apresentou a maior taxa de detecção viral (Albinana-Gimenez et al., 2009).

O TTV é transmitido pela via fecal-oral e pode ser detectado por meio de ensaios moleculares que possuem características de sensibilidade e rapidez como, por exemplo, a PCR (Griffin et al., 2008), que nos últimos anos tem sido utilizada para detecção de vírus em amostras ambientais (Katayama et al., 2002 e Ley et al., 2002). O desenho de oligonucleotídeos para detecção de TTV muitas vezes está voltado para a amplificação de sequências de uma região codificante, com sucesso para detectar TTV do grupo 1, ao passo que para detectar TTV de todos os grupos conhecidos normalmente têm sido utilizados iniciadores baseados em uma região não codificante (Okamoto et al., 1998; 2000c). Além disso, regiões conservadas do genoma viral 
podem constituir alvos capazes de permitir a detecção de um número maior de amostras de TTV, mesmo de genogrupos não conhecidos (Devalle \& Niel 2004).

O uso da PCR é de grande importância na deteç̧ão de contaminação por vírus em amostras ambientais, principalmente pelo fato de que muitas vezes os agentes virais estão extremamente diluídos nas amostras de água, necessitando, portanto, de uma técnica de elevada especificidade para sua detecção (Vaidya et al., 2002). Essa metodologia ainda tem o benefício adicional da determinação de sequências específicas do material genético detectado, auxiliando na caracterização dos agentes encontrados por filogenia molecular. A principal desvantagem é que a PCR ou outros métodos de detecção molecular não permitem distinguir partículas virais viáveis de partículas não infecciosas na amostra em teste, o que só é possível complementando os ensaios com cultivos celulares (Tavares et al., 2005).

No caso específico da detecção de TTV em amostras de água, vários estudos têm revelado o aspecto promissor deste agente, quando analisado ao lado de outros agentes virais, como marcador de poluição fecal (Griffin et al., 2008). Mesmo no Brasil, outros grupos de pesquisa já obtiveram resultados de extrema relevância sobre a relação entre TTV e poluição fecal. O relato mais recente no país refere-se à cidade de Manaus (Diniz-Mendez et al., 2008), em estudo no qual foi utilizada a coleta de amostras de 2 litros de água da bacia de cursos d'água que atravessam a cidade, seguida de concentração viral de acordo metodologia descrita anteriormente (Katayama et al., 2002) com algumas modificações, extração de material genômico viral conforme métodos usuais e detecção por metodologia molecular por reação em cadeia da polimerase (PCR) em tempo real (qPCR) comparada à PCR convencional. Os pesquisadores observaram a presença de TTV em 92\% das amostras de água analisadas e processadas por qPCR. Na mesma pesquisa também foram analisadas as amostras seguindo a metodologia por PCR convencional, na qual o resultado positivo para o TTV foi de $36,5 \%$.

\section{TTV COMO MARCADOR DE POLUIÇÃO AMBIENTAL}

No atual sistema de abastecimento e monitoramento da qualidade e potabilidade da água, somente os coliformes totais e Escherichia coli são parâmetros indicadores de contaminação fecal. Sabe-se que estes indicadores bacterianos não asseguram total proteção à saúde pública, visto que muitas doenças de origem viral podem ser oriundas de águas nas quais a ausência de bactérias tenha sido detectada, além de se observar que após o tratamento da água ainda se observa a presença do TTV e de outros vírus (Griffin et al., 2008). Além disso, estudos relatam elevada presença de TTV em águas antes e após tratamento. No Japão, o TTV foi detectado em 97\% das amostras de esgoto, sendo $18 \%$ antes da cloração e $24 \%$ após a cloração, o que indica que o vírus estava amplamente disseminado na população japonesa durante um ano de estudo (Haramoto et al., 2005a). Tais dados podem ser comparados com o estudo realizado por Vaidya et al. (2002), na Índia, no qual observaram a presença 
de $14,5 \%$ e $2 \%$ de amostras positivas para o TTV, respectivamente antes e após tratamento, o que significa prevalência muito mais baixa.

Não existem ainda dados tomados de forma semelhante para a Região Sul do Brasil. Até o momento nosso grupo de pesquisa vem realizando experimentos com diversos agentes virais, entre os quais se destacam Torque teno vírus, Adenovírus e Enterovirus. Estamos avaliando amostras de diferentes origens, como água de rio, amostras de estações de tratamento, água mineral e efluentes de origem pecuária. A metodologia para a concentração de tais amostras segue protocolo modificado de Katayama et al. (2002), seguido de extração viral por meio de sistemas comerciais de extração de genomas virais conforme as orientações do fabricante e realização da técnica de amplificação por PCR de fragmentos altamente conservados do gene ORF2, utilizando iniciadores desenhados originalmente para este trabalho.

Nossos resultados, embora preliminares, têm demonstrado uma maior prevalência do Adenovírus e do Enterovirus. O TTV mostrou-se presente em aproximadamente $10,7 \%(3 / 28)$ das amostras analisadas, diferentemente dos estudos realizados no norte do país e no Japão, mas em situação semelhante ao que foi observado na Índia. Como indicam os dados, a ocorrência do TTV é apenas esporádica em água previamente considerada contaminada em nossa região, quando se compara com outros agentes virais. Para a certificação de tais resultados mais amostras devem ser analisadas.

\section{PERSPECTIVAS}

Novos estudos devem ser realizados com o propósito de investigar o comportamento e o papel de vírus entérico na natureza. É importante buscar métodos e protocolos que passem a fazer parte das rotinas dos sistemas de monitoramento de águas e esgoto, nos quais as metodologias disponíveis sejam de grande valia no desenvolvimento de um sistema inovador e complementar à análise de contaminação fecal da água, bem como à análise do impacto causado ao ambiente relacionado à ocupação humana. Além disso, são necessários novos estudos que envolvam a pesquisa do TTV, associada ou não à detecção de outros agentes virais, buscando relacionar a possibilidade de este vírus estar associado ao desenvolvimento de patologias em humanos e animais.

Até o momento não há evidências do desenvolvimento de doenças diretamente associadas à presença deste vírus, assim como não há manifestações clínicas exclusivas do TTV. Portanto, é necessária a realização de estudos complementares que levem à compreensão da biologia e especialmente das estratégias de disseminação deste agente em populações humanas e animais. Neste momento, estamos realizando estudos com esta finalidade no sul do país, tentando aplicar tais metodologias à análise e validação destes e outros agentes como marcadores de poluição fecal do ambiente, tanto em ambientes urbanos quanto em criações pecuárias. 


\section{AGRADECIMENTOS}

ADV realiza seus estudos de mestrado com uma bolsa CAPES-PROSUP. FRS é bolsista de Produtividade do CNPq nível 2.

\section{ABSTRACT}

Torque teno virus (TTV) and fecal pollution

The search for viral agents in environmental water samples started around sixty years ago. Initially, the research focus was on detection of Enteroviruses. More recently other viral agents, especially enteric viruses with major impact on public health, also became targets of research in water samples. These viral agents, generally associated with gastroenteritis and hepatitis, have as main characteristics the excretion in high amounts in faeces of infected individuals, high resistance to destruction in the environment and absence of replication outside the host. These biological characteristics make them excellent candidates as markers of environmental contamination due to settling of new areas by human beings, as well as detect imperfections in the strategies of basic sanitation. More recently, the Torque Teno virus (TTV) is being considered an interesting candidate as a biological marker in the study of faecal contamination of the water, for keeping the characteristics previously mentioned for the enteric viruses and to be widely spread in the human population.

KEY WORDS: Torque Teno virus. TTV. Biomarkers. Environmental impact.

\section{REFERÊNCIAS}

1. Abe K, Inami T, Asano K, Miyoshi C, Masaki N, Hayashi S, Ishikawa K, Takebe Y, Win KM, El-Zayadi AR, Han KH, Zhang DY. TT virus infection is widespread in the general populations from different geographic regions. J Clin Microbiol 37: 2703-2705, 1999.

2. Albinana-Gimenez N, Clemente-Casaresa P, Calgua B, Huguetb JM, Courtois S, Girones R. Comparison of methods for concentrating human adenoviruses, polyomavirus $\mathrm{JC}$ and noroviruses in source waters and drinking water using quantitative PCR. J Virol Methods 158: 104-109, 2009.

3. Bassit L, Takei K, Hoshino-Shimizu S, Nishiy AS, Sabino EC, Bassitt RP, Focaccia R, D'Amico E, Chamone DF, Ribeiro-Dos-Santos G. New prevalence estimate of TT virus (TTV) infection in lowand high-risk population from São Paulo, Brazil. Rev Inst Med Trop São Paulo 44: 233-234, 2002.

4. Berns KI. Parvoviridae: The virus and their replication. In: Fields BN et al. Fields virology, 3 ed. Philadelphia, Lippincot-Raven, 1996. p. 2173-2199.

5. Brassard J, Gagne MJ, Lamoureux L, Inglis GD, Leblanc D, Houde A. Molecular detection of bovine and porcine Torque Teno Vírus in plasma and feces. Vet Microbiol 126: 271-276, 2008.

6. Devalle S, Niel C. Distribution of TT virus genomic groups 1 to 5 in Brazilian blood donors, HBV carriers, and HIV-1- infected patients. J Med Virol 72: 166-173, 2004.

7. Devalle S, Niel C. Multiplex PCR assay able to simultaneously detect Torque teno virus isolates from phylogenetic groups 1 to 5. Braz J Med Biol Res 38: 853-860, 2005. 
8. Diniz-Mendes L, De Paula VS, Luz SLB, Niel C. High prevalence of human Torque teno virus in streams crossing the city of Manaus, Brazilian Amazon. J Appl Microbiol 105: 51-58, 2008.

9. Diniz-Mendes L, Devalle S, Niel C. Genomic Characterization of a Brazilian TT Virus Isolate Closely Related to SEN Virus-F. Mem Inst Oswaldo Cruz 99: 301-306, 2004.

10. Dore WJ, Henshilwood K, Lees DN. Evaluation of F-specific RNA bacteriophage as a candidate human enteric virus indicator for bivalve molluscan shellfish. Appl Environ Microbiol 66: 1280-1285, 2000.

11. Duran A, Muniesa EM, Mendez X, Valero F, Lucena F, Jofre J. Removal and inactivation of indicator bacteriophages in fresh waters. J Appl Microbiol 92: 338-347, 2002.

12. Fong TT, Lipp, EK. Enteric Viruses of Humans and Animals in Aquatic Environments: Health Risks, Detection, and Potential Water Quality Assessment Tools. Microb Mol Biol Rev 69: 357-371, 2005.

13. Griffin JS, Plummer JD, Long SC. Torque teno virus: an improved indicator for viral pathogens in drinking waters. J Virol 5: 112, 2008.

14. Haramoto E, Katayama H, Ohgaki S. Detection of noroviruses in tap water in Japan by means of a new method for concentrating enteric viruses in large volumes of freshwater. Appl Environ Microbiol 70: 2154-2160, 2004.

15. Haramoto E, Katayama H, Oguma K, Yamashita H, Nakajima E, Ohgaki S. One-year monthly monitoring of Torque teno virus (TTV) in wastewater treatment plants in Japan. Water Res 39: 2008-2013, 2005a.

16. Haramoto E, Katayama H, Oguma K, Ohgaki S. Application of cation-coated filtermethod to detection of noroviruses, enteroviruses adenoviruses and torque teno viruses in the Tamagawa River in Japan. Appl Environ Microbiol 71: 2403-2411, 2005b.

17. Itoh Y, Takahashi M, Fukuda M, Shibayama T, Ishikawa T, Tsuda F, Tanaka T, Nishizawa T, Okamoto H. Visualization of TT virus particles recovered from the sera and feces of infected humans. Biochem Biophys Res Commun 279: 718-724, 2000.

18. Jiang SC, Chu W, He JW. Seasonal Detection of Human Viruses and coliphage in Newport Bay, California. Appl Environ Microbiol 73: 6468-6474, 2007.

19. Kakkola L. Human Torque teno virus: epidemiology, cell biology and immunology. Finland [Master thesis in Virology, Haartman Institute, Department of Virology University of Helsinki], 2008.

20. Katayama H, Shimasaki A, Ohgak IS. Development of a Virus Concentration Method and its application to detection of Enterovirus and Norwalk Virus from Coastal Seawater. Appl Environ Microbiol 68: 1033-1039, 2002.

21. Ley V, Higgins J, Fayer R. Bovine Enteroviruses as Indicators of Fecal Contamination. Appl Environ Microbiol 68: 3455-3461, 2002.

22. Maggi F, Andreoli E, Riente L, Meschi S, Rocchi J, Sedie DA, Vatteroni ML, Ceccherini-Nelli L, Specter S, Bendinelli M. Torquetenovirus in patients with arthritis. Rheumat 46: 885-886, 2007.

23. Mckeown NE, Fenaux M, Halbur PG, Meng XJ. Molecular characterization of porcine TT virus, an orphan virus, in pigs from six different countries. Vet Microbiol 104: 113-117, 2004.

24. Mehnert DU. Reuso de efluente doméstico na agricultura e a contaminação ambiental por vírus entéricos humanos. Rev Inst Biológico 65: 19-21, 2003.

25. Mushahwar IK, Erker JC, Muerhoff SA, Leary TP, Simons JN, Birkenmeyer LG, Chalmers ML, Pilot-Matias TJ, Dexai SM. Molecular and biophysical characterization of TT virus: Evidence for a new virus family infecting humans. Proc Natl Acad Sci 96: 3177-3182, 1999.

26. Nasser TF. Deteç̧ão do Torque Teno Vírus em pacientes infectados e em indivíduos expostos ao HIV na região norte do Paraná. Paraná [Tese de Mestrado em Patologia Experimental, Universidade Estadual de Londrina.], 2007.

27. Nishizawa T, Okamoto H, Konishi K, Yoshizawa H, Miyakawa Y, Mayumi M. A novel DNA virus (TTV) associated with elevated transaminase levels in posttransfusion hepatitis of unknown etiology. Biochem Biophys Res Commun 241: 92-97, 1997. 
28. Okamoto H, Akahane Y, Ukita M, Fukuda M, Tsuda F, Miyakawa Y, Mayumi M. Fecal excretion of a nonenveloped DNA virus (TTV) associated with posttransfusion non-A-G hepatitis. J Med Virol 56: 128-132, 1998.

29. Okamoto H, Fukuda M, Tawara A, Nishizawa T, Itoh Y, Hayasaka I, Tsuda F, Tanaka T, Miyakawa Y, Mayumi M. Species-Specific TT Viruses and Cross-Species Infection in Nonhuman Primates. $J$ Virol 74: 1132-1139, 2000a.

30. Okamoto H, Ukita M, Nishizawa T, Kishimoto J, Hoshi Y, Mizuo H, Tanaka T, Miyakawa Y, Mayumi M. Circular Double-Stranded Forms of TT Virus DNA in the Liver. J Virol 74: 5161-5167, $2000 \mathrm{~b}$.

31. Okamoto H, Takahashi M, Kato N,Fukuda M, Tawara A, Fukuda S, Tanaka T, Miyakawa Y, Mayumi M. Sequestration of TT virus of restricted genotypes in peripheral blood mononuclear cells. J Virol 74: 10236-10239, 2000c.

32. Pinho JRR, Takahashi DA, Fava ALB, Gonçales NSL, Carrilho FJ, Stucchi RSB, Gonçales FLJ, Silva LCD, Soares MCP, Bensabath G, Buck GA, Meyers GA, Bernardini PA. Transfusiontransmited virus (TTV) in Brazil. preliminary report. Rev Inst Med Trop São Paulo 40: 335-336, 1998.

33. Resolução Consema n ${ }^{\circ}$ 128/2006. Estado do Rio Grande do Sul - Secretaria do Meio Ambiente, Conselho Estadual do Meio Ambiente - CONSEMA. Disponível em www.sema.rs.gov.br/sema/ jsp/consema_resolucao_lista_ano 2006.

34. Takahashi K, Hoshino $\bar{H}$, Ohta Y, Yoshida N, Mishiro S. Very high prevalence of TT virus (TTV) infection in general population of Japan revealed by a new set of PCR primers. Hepatol Res 12: 233-239, 1998.

35. Tavares TM, Cardoso DDP, Brito WMED. Vírus entéricos veiculados por água: aspectos microbiológicos e de controle de qualidade da água. Rev Patol Trop 34: 85-104, 2005.

36. Teixeira JC, Leal FCT. Desafios no controle de doenças de veiculação hídrica associadas ao tratamento e ao abastecimento de água para consumo humano. In: VI Simpósio ítalo brasileiro de engenharia sanitária e ambiental, Vitoria, 2002.

37. Vaidya SR, Chitambar SD, Arankalle VA. Polymerase chain reaction-based prevalence of hepatitis A, hepatitis E and TT viruses in sewage from an endemic area. $J$ Hepat 37: 131-136, 2002.

38. Watanabe MAE, Miranda HC, Oliveira KB, Oliveira CEC, Tristão FSM, Duarte LM, Silva LL, Corte AC, Guarnier FA, Kaminami MS. Aspectos patológicos, imunológicos e propriedades moleculares do TT vírus. J Bras Patol Med 41: 223-228, 2005. 